\title{
A retórica da pós-verdade: o problema das convicções
}

\section{Rodrigo Seixas}

Doutorando e Mestre em Estudos Linguísticos pela Universidade Federal de Minas Gerais (UFMG), Brasil.

rodrigoseixaspb@uol.com.br

Resumo: Eleita “palavra do ano” de 2016 pelos Dicionários Oxford, a pós-verdade é o qualificativo das circunstâncias em que fatos objetivos são menos influentes na opinião pública que os apelos emocionais e as crenças pessoais. Assim posto, seria a pós-verdade não apenas um sinônimo de fake news, mas, sobretudo, de convicção (ANGENOT), vez que, falsas ou verdadeiras, as informações são divulgadas ou excluídas não pela sua veridicidade, mas pela sua adequação às crenças/valores de cada sujeito. Tal indisponibilidade à verificação se daria, em tese, por razão do tipo de racionalidade instrumental, pragmatista e utilitarista (BOUDON), que configura a cognição e a retórica dos sujeitos. Interessa a este artigo, portanto, não o funcionamento e a circulação dos discursos de pós-verdade, mas problematizar o tipo de racionalidade contemporânea como causa do fenômeno, a ponto de se tornar um conceito tão discutido nas Ciências Humanas e Sociais como um todo.

Palavras-chave: Pós-verdade. Convicção. Retórica. Fake news.

Abstract: Oxford's 2016 "Word of the Year", post-truth is the qualifier of circumstances in which objective facts are less influential on public opinion than emotional appeals and personal beliefs. Of course, post-truth would not only be synonymous with fake news, but especially with conviction (ANGENOT), because, true or false, pieces of information are either disclosed or excluded not by their veracity, but by their adaptation to beliefs/values of each individual. Such unavailability of verification would in theory be due to the type of pragmatic and utilitarian rationality (BOUDON) that shapes the cognition and rhetoric of individuals. The interest of this article is therefore not the operation/circulation of posttruth discourses, but rather the questioning of contemporary rationality as the cause of the phenomenon, to the point of becoming a concept much debated in the human and social sciences as a whole.

Keywords: Post-truth. Conviction. Rhetoric. Fake news. 
Introdução

"Os humanos argumentam constantemente e em todas as circunstâncias, mas, em verdade, pouco e raramente se persuadem reciprocamente" (ANGENOT, 2008, p. 07, tradução nossa). A grande postulação de Angenot quanto à tamanha impersuasão recíproca parece ser cada vez mais o tom da contemporaneidade. Incontáveis informações passam diante dos nossos olhos todos os dias, algumas verdadeiras, bem fundamentadas, factuais, outras tantas falsas, vestidas, no entanto, com a fantasia da verdade. A camisa é da verdade, a calça é da verdade, os sapatos são da verdade, todavia, o corpo e a alma, conteúdos principais, mostram-se, no mais das vezes, falsos. É um "corpo de pós-verdade", diria boa parte de teóricos e intelectuais acerca desse fenômeno tão em evidência nos dias atuais. De fato, muito se tem discutido sobre a "era da pós-verdade" neste mundo em que as fake news tomam o lugar das verdades de fato. Poder-se-ia aqui citar inúmeros exemplos de acontecimentos em que as fake news controlaram, ou ao menos influenciaram, as narrativas que se construíram em torno de um evento, como, por exemplo, na greve dos caminhoneiros e no assassinato da vereadora Marielle Franco e de seu motorista, Anderson Pedro Gomes. Em ambos os casos, foi possível presenciar a divulgação de inúmeras informações falsas, as quais foram amplamente compartilhadas por pessoas que se animavam com tais informações, porquanto elas movimentavam o "espírito" de maneira semelhante, por uma partilha de convicções.

De fato, a difusão dessas informações é assunto basilar para o entendimento do fenômeno da pós-verdade e de sua relação com as fake news. O que aqui se pretende problematizar, no entanto, não é a difusão, mas a própria razão de existência desse fenômeno. Quanto a isso, defende-se, neste artigo, que o problema da pós-verdade está atrelado, para além da oposição verdade/mentira e da difusão de fake news, à questão das convicções.

Alheio à distinção entre convicção e persuasão em Perelman e OlbrechtsTyteca (2005 [1958], p. 29-34), entende-se o conceito, aqui, nos termos de Angenot (2008), para quem a convicção política é questão de crença, sólida que seja, mas obedece às mesmas estruturas de funcionamento das crenças religiosas e de tantas outras. Pode-se afirmar, entretanto, que toda crença estabelece uma racionalidade, e que as opiniões e as ações, produtos dessa racionalidade, possibilitam compreender a própria dinâmica de validação das verdades de cada grupo. Para Boudon (2017), a propósito, haveria, em tempos 
atuais, o primado de uma racionalidade instrumental (BOUDON, 2017), utilitarista/pragmatista, que traz para o centro da racionalidade as razões axiológicas e patêmicas de cada sujeito, em detrimento de outras formas de validade das verdades no mundo. Haveria, assim, acredita-se, um movimento pelo desejo de verdade que se confundiria com a própria verdade e que serviria de explicação, ao menos em parte, da grande disposição dos sujeitos pela divulgação de opiniões baseadas em fake news ou em informações frágeis.

\section{A pós-verdade: entre a mentira e a verdade na política}

Vivemos em uma era de pós-verdade 1 . Assim afirma o autor Ralph Keyes em um de seus livros. O termo tem sido objeto de discussão crescente nos últimos dois anos, desde que escolhido pelo dicionário Oxford como a palavra do ano de 2016. Conforme se verá adiante, trata-se de um adjetivo, porquanto aparece freqüentemente qualificando o nome "politics" [política], como em the post-truth politics. Consoante os julgadores, apesar de o termo composto ser já catalogado desde o ano de 1992 - identificado em um ensaio do dramaturgo Steve Tesich, na revista Nation-, apenas no ano de 2016 o termo ganhou larga importância na discussão política, e também acadêmica, ao redor do mundo, com sua ocorrência na descrição de dois eventos de extrema importância para a política mundial, o Brexit e a candidatura de Donald Trump à Presidência dos Estados Unidos. Sem dúvida, desde então, a discussão sobre pós-verdade ganhou imensa notoriedade em diversos países do mundo, sobretudo na proximidade de algum pleito, como é o caso do Brasil. No entanto, apesar de correntemente bastante debatida, muito se tem confundido acerca do que vem a ser o fenômeno. Antes de avançar na conceituação do termo, é importante dissociar o que não é pós-verdade ou o que apenas o é em complementariedade, mas não necessariamente fazendo parte de seu escopo conceitual.

1.1. O discurso da pós-verdade não é necessariamente sinônimo de mentira (embora possa, obviamente, tratar-se de uma)

A mentira na política não é algo novo e a sua existência já é discutida há muito tempo. Em um dos maiores clássicos da política, O Príncipe, Maquiavel (2010, p. 105) afirma que os homens "são tão simplórios e obedientes às necessidades imediatas que aquele que engana sempre encontrará quem se

\footnotetext{
1 "We live in a post-truth era" (posição 231). Originalmente, esta frase é tributada a Steve Tesich (1992) e retomada por Keyes (2004).
} 
deixe enganar". De fato, a mentira é sempre assunto recorrente na política e muitos estudiosos do discurso político têm se debruçado para compreender o seu funcionamento enquanto ato discursivo inerente à natureza social do homem. Quanto a isso, Keyes (2004) salienta que a ferramenta da mentira (ou do engano) é própria da constituição do Homo Sapiens, uma espécie de desenvolvimento cognitivo em prol da sobrevivência da espécie.

A problemática da mentira no conceito de pós-verdade aparece já na própria morfossemântica do termo. Trata-se do uso do prefixo "pós", que indica, de antemão, a natureza da relação pretendida com a noção de verdade. Segundo o próprio dicionário Oxford, o prefixo pós, nos últimos anos, deixa de significar meramente "o tempo após um evento ou uma situação específica" para significar o que caracteriza algo "pertencente a um tempo no qual o conceito específico se tornou irrelevante ou desimportante" ". Ainda em termos de referência, o dicionário online Dicio 4 reserva para o afixo "pós" os seguintes significados: 1- "Elemento de composição de palavras (prefixo) que dá a ideia do que é posterior, do que ocorre após, no espaço e no tempo: pós-graduação, após a graduação"; 2- "Prefixo que atribui um juízo de valor negativo, desvalorizando o conceito ao qual está ligado: pós-verdade". Vê-se aí, destarte, que, assim como encontrado no dicionário Oxford, há um distinto significado para o prefixo "pós" quando se tratando de alguns conceitos considerados defasados ou vulnerabilizados no tempo, como é o caso de "pós-verdade".

Todavia, este caso prefixal, em especial, parece não significar, logicamente, nem um período após a verdade em termos temporais, nem tampouco totalmente a sua descredibilização. O que ocorre, com efeito, é uma superação do desejo de verdade por parte dos sujeitos, ao menos da verdade divergente da sua. Por assim dizer, haveria certo desinteresse dos sujeitos em estabelecer um movimento heurístico de verificação dos fatos e das verdades, porquanto mais vale a manutenção das convicções e das identidades do que um verificacionismo a todo custo. Não há, logo, preocupação em checar os fundamentos e fontes de uma verdade, já que há sempre uma leitura pré-programada dos sujeitos, enviesada, por certo, dos eventos sociais.

\footnotetext{
${ }^{2}$ No original: "referring to the time after a specified situation or event".

${ }^{3}$ No original: "belonging to a time in which the specified concept has become unimportant or irrelevant".

4 “Pós". In: Dicio, dicionário online. Disponível em: https://www.dicio.com.br/pos/. Acesso em 28. Ago. 2018.
} 
Atribui-se a Joseph Goebbels, propagandista do regime nazista na Segunda Guerra, a célebre frase: "uma mentira contada mil vezes torna-se verdade", o que apontaria para uma relatividade ou, ao menos, uma fragilidade da noção de "verdade". No entanto, segundo afirma Emediato (2016, p. 17), "as verdades, por serem relativas, dependem essencialmente dos seus domínios de validação". O autor estabelece, assim, alguns domínios e critérios: no domínio científico, por exemplo, os critérios são metodológicos e epistemológicos, e fornecem as bases epistêmicas de validação e de falseamento; no jurídico, as bases são deônticas; no religioso, as bases "são epifânicas e não são verificáveis, portanto não falseáveis [... ]"; e no político, as bases de validação são "ideológicas, o que torna as verdades discursivas e retóricas" (EMEDIATO, 2016, p. 17).

Por conseguinte, em se entendendo a verdade como efeito do discurso, pode-se considerar a realidade social e política como uma coconstrução humana. Essa afirmação pode soar um tanto estranha, na medida em que existem situações que independem do desejo de sentido de qualquer sujeito. Uma árvore é uma árvore e não é um carro; não há grandes discussões acerca deste estatuto, a não ser quando se trata de fenômenos ou objetos cuja existência ainda é fruto de polêmica. Tal é o caso, por exemplo, do estatuto de Plutão como um planeta ou dos fetos anencéfalos como seres humanos, casos em que as categorias conceituais de planeta e de ser humano são elas próprias objetos de discussão 5 .

Por certo, se já em assuntos de ordem biológica ou física há importante discussão sobre a veracidade de alguns fatos ou fenômenos, ainda mais estão passíveis de polemicidade e, consequentemente, de conflito, as verdades existentes no discurso social, fortemente imbuído do fator moral e ideológico. Isso porque a realidade social se mostra de outra natureza, posto que não aceita como sua característica fundamental o princípio da necessidade, isto é, a lógica do pensamento que considera uma proposição como irrenunciavelmente verdadeira ou irrenunciavelmente falsa. Sendo assim, não há espaço, nas proposições necessárias, para o que é da ordem do contingente, a saber, para a lógica que institui uma proposição como possível

\footnotetext{
${ }^{5}$ Não há dúvidas, entretanto, que se tratam aí de dois casos distintos. No primeiro, está em questão uma definição científica, epistemológica sobre o que vem a ser entendido como planeta. É, portanto, uma polêmica restrita ao campo científico. Diferentemente, na polêmica com os fetos anencéfalos, há um fator moral preponderante na discussão conceitual, um estatuto axiológico irrevogável, de maneira que faz a polêmica ser estendida para além do campo da ciência e da medicina, por exemplo, para ser discutida também nos mais diversos campos do discurso social.
} 
de ser verdade sem o ser necessariamente. É justamente por isso que o discurso social é o lugar do contingente, onde não há verdade última, mas apenas verdades relativas, verossimilhanças, possibilidades e probabilidades de verdade. A esse respeito, Emediato (2016, p. 16) afirma: "as verdades são construções sociais e humanas, podem ser explicadas, justificadas, relativizadas, validadas, falseadas e hierarquizadas".

Diz o adágio popular, no entanto, que contra fatos não há argumentos, o que em si não é necessariamente verdade. Segundo Perelman e OlbrechtsTyteca (2005), os fatos, bem como as verdades, dizem respeito ao que é amplamente aceito por um auditório universal. Por assim dizer, a amplitude de aceitação de um fato ou de uma verdade segue a lógica do que é comum a vários entes pensantes e poderia ser comum a todos. Para eles, os fatos e verdades seriam “objetos de acordo pertencentes ao real” (p. 75, grifo nosso). No entanto, o real também é em si mesmo objeto de debate. Perelman e Olbrechts-Tyteca afirmam que "a concepção que as pessoas têm do real pode, em largos limites, variar conforme as opiniões filosóficas professadas" (p. 74). Adiciona-se, aqui, que pode variar, igualmente, conforme a ideologia que as assujeita ou, melhor dizendo, que as programa a agir discursivamente de um modo e não de outro.

Ademais, sabe-se que, para os estudos discursivos, o real não se liga, necessariamente, ao discurso, da mesma forma que não se pode relacionar diretamente um discurso que se pretenda verdadeiro com uma irrenunciável verdade em si mesma. Em outras palavras, nem todo ato de linguagem garante, nesse sentido, uma ligação imediata com a realidade, como se a linguagem Ihe fosse a imagem fiel, uma representação exata. Não à toa, falase bastante em efeitos de real (BARTHES, 1971), como também em efeitos de verdade (FOUCAULT, 1979), na medida em que seria o ato de linguagem um efeito e, como tal, não se pode concebê-lo forçadamente duradouro, tampouco absoluto.

Dito isso, é necessário considerar que, apesar de a partilha do sentido ser condição da comunicação, é também comum às interações sociais a divergência no que se refere à apreensão da realidade. Se todo fato social tem o potencial de gerar distintas interpretações, no mais das vezes, tais interpretações se chocam e são mesmo antagônicas entre si. Ademais, o problema das versões que se constroem sobre um fato se intensifica por estas serem, em todo momento, reconstruídas à medida que aparecem fatos novos, 
em boa parte fake news, e que colocam o estatuto de veridicidade das notícias em xeque, assemelhando-se mesmo à velha brincadeira do "telefone sem fio".

Em suma, a questão da mentira e da verdade no discurso político, sobretudo na sua face mediatizada, é profundamente controversa, porquanto se confundem, no mais das vezes, uma com a outra. A diferença entre elas, no fim das contas, reside na questão da utilidade, leia-se, com isso, o interesse que cada sujeito tem em determinada opinião ou crença, supostamente verdadeiras por fazerem parte de seu conjunto de pressupostos ideológicos de existência no mundo e de leitura da realidade. É, por conseguinte, sempre um ato pragmático e axiológico. Emediato (2016, p. 15), em consonância, afirma que "toda mentira possui uma pretensão à verdade" e "o que distingue a verdade da mentira não é nada formal, mas sua natureza pragmática, genérica e intencional, de um lado, e suas condições de validade, de outro".

1.2. A pós-verdade não corresponde necessariamente às fake news, mas elas lhe são inegavelmente uma das faces

Por certo, a discussão sobre pós-verdade emerge em consonância com o fenômeno das fake news, o que nos faz, invariavelmente, ligar um fenômeno ao outro. No entanto, alguns comentários merecem ser tecidos a esse respeito. O primeiro deles concerne à natureza das fake news em comparação com o conceito de pós-verdade. Segundo Braga (2018, p. 205), o fenômeno das fake news pode ser entendido como "a disseminação, por qualquer meio de comunicação, de notícias sabidamente falsas com o intuito de atrair a atenção para desinformar ou obter vantagem política ou econômica". Por essa ótica, pode-se considerar que há, por parte do(s) sujeito(s) que veicula $(m)$ tais notícias, uma certa vontade de desinformar o seu interlocutor e levá-lo, ao menos potencialmente, a um estado de dissuasão referente à sua disposição de espírito anterior acerca de qualquer assunto.

Em contrapartida, Christian Dunker (2017) acentua que:

[...] alguns consideram que o discurso da pós-verdade corresponde a uma suspensão completa de referência a fatos e verificações objetivas, substituídas por opiniões tornadas verossímeis apenas à base de repetições, sem confirmação de fontes. Penso que o fenômeno é mais complexo que isso, pois ele envolve uma combinação calculada de observações corretas, interpretações plausíveis e fontes confiáveis em uma mistura que é, no conjunto, absolutamente falsa e interesseira (DUNKER, 2017, p. 38). 
Há nesses discursos, por assim dizer, enunciados comprovadamente verdadeiros, relação a fatos efetivamente comprovados, interpretações plausíveis, induções verossímeis, o que confere ao fenômeno da pós-verdade traços para além da velha mentira política. Dizer, por exemplo, como ocorrido nesta semana final de agosto, que a candidata à Presidência, Marina Silva, teria invadido uma fazenda, no Acre, em 1986, de maneira semelhante aos atos do Movimento dos Trabalhadores Rurais Sem Terra (MST) ${ }^{6}$, é tão simplesmente mentira. É uma fake news, na medida em que se trata de uma "notícia falsa", mas não passa, em se analisando profundamente a sua estrutura discursiva, de uma mentira com fins político-eleitorais, difundida nas redes sociais. Há inúmeros outros exemplos, como uma pretensa carta atribuída a Lulu Santos, na qual o artista pedia reforma política?

O que se pode perceber de comum entre todas essas manifestações discursivas é que há, de fato, um traço manipulatório em tais discursos; há sempre um movimento de construção retórico-discursiva em cima de paixões, valores e convicções dos diferentes sujeitos por parte dos sujeitos produtores desses discursos, com o intuito de persuadir tão simplesmente, sem uma relação necessária com a "verdade dos fatos". No entanto, não necessariamente se tratam de simples mentiras. O que se percebe mormente é que nem sempre o processo é consciente e intencional, como normalmente se espera dos atos de manipulação, mas, em alguns casos, trata-se de reproduções automáticas, por razão de uma pré-programação própria à natureza das convicções.

Há que se distinguir, portanto, o conteúdo do continente. Nem todo discurso de pós-verdade corresponde a uma mentira comprovada, assim como nem sempre obedece a uma intencional estratégia manipuladora dos sujeitos produtores do discurso; tampouco são as fake news, em todo caso, divulgadas também intencionalmente com o intuito de dissuadir pessoas, levando-as à desinformação. Em certas situações, tais notícias falsas são divulgadas pura e simplesmente por corresponderem às convicções já antecipadamente instituídas. Poder-se-ia dizer, logo, que toda mentira, fake news e manipulação

\footnotetext{
6 "FOLHA DE SÃO PAULO. Marina Silva não invadiu fazenda, como sugere viral enganoso de redes sociais. Folha de São Paulo. São Paulo, 24 Ago. 2018. Disponível em: https://www1.folha.uol.com.br/poder/2018/08/marina-silva-nao-invadiu-fazenda-como-sugere-viralenganoso-de-redes-sociais.shtml. Acesso em 28 Ago. 2018.

7 TEIXEIRA, Lucas Borges. Lulu Santos repudia falsa carta atribuída a ele pedindo reforma na política. Uol Notícias. São Paulo, 02 Jul. 2018. Disponível em:https://noticias.uol.com.br/confere/ultimas-noticias/2018/07/02/lulu-santos-repudia-cartaatribuida-a-ele-que-prega-reforma-na-politica.htm. Acesso em: 28 Ago. 2018.
} 
fazem parte do conjunto de discursos que compreendem a "pós-verdade", no entanto, esta a tais faces não se resume. Ela pode, conforme apresentado, conter, em meio às informações falsas, outras tantas informações verdadeiras, ou verossímeis, portanto retóricas, o que impossibilita afirmar categoricamente que o critério formal para reconhecimento de um discurso de pós-verdade seja o de veicular mentiras comprovadas.

\subsection{O conceito de pós-verdade e a formação da opinião pública}

Segundo o dicionário Oxford, o termo é:

[...] um adjetivo definido como 'relatando ou denotando circunstâncias em que fatos objetivos são menos influentes na opinião pública que os apelos emocionais e as crenças pessoais (OXFORD, 2016).

Parece óbvio que, em um primeiro momento, entenda-se a opinião pública como naturalmente o lugar das razões comuns a uma coletividade. Ora, para Charaudeau (2013, p. 23), "a opinião não é conhecimento mas julgamento" 8 , o que significa dizer, portanto, que toda opinião é um ato subjetivo (e relativo) de interpretação da realidade, no qual incidem os valores responsáveis pela interpretação dos fatos e das verdades de um modo e de outro. Não obstante, apesar de subjetivo, é também desejo de compartilhamento, na medida em que os sujeitos tentam fazer valer a sua opinião sobre as demais. Isso é importante de salientar, posto que, ao falar de opinião pública como uma opinião coletiva, esquece-se que ela é formada pelas subjetividades das opiniões pessoais. Como assinala Charaudeau (2013), não há palavra coletiva, na medida em que o ato de enunciação é sempre o ato de um indivíduo. Entretanto, desde o seu nascimento, o ser humano está "mergulhado na alteridade", de modo que não se constitui o ser individual sem o ser coletivo.

Nessa perspectiva, não há como considerar haver um universal da opinião pública, um ideal de homogeneidade, um máximo denominador comum. Pelo contrário, Charaudeau (2013) afirma ser a opinião o menor denominador comum, posto que a diferença é muito mais a regra que a exceção e que, portanto, as pessoas se reuniriam em torno de um mínimo de crenças compartilhadas.

\footnotetext{
${ }^{8}$ No original: “L'opinion n'est pas connaissance mais jugement”.
} 
O que se acentua na era da pós-verdade, entretanto, é a indisponibilidade ao diálogo entre as distintas opiniões, pela consideração, valorativa, por certo, de já se conhecer a "única verdade possível” sobre determinada questão. Isso se dá devido à existência de um conjunto de vieses cognitivos, dentro os quais o viés de confirmação, a saber, a tendência em tratar, preferencialmente, as informações que confirmem nossas crenças em detrimento das que as invalidam (BRONNER, 2013).

A pós-verdade evocaria, assim, um autoritarismo da interpretação, que impele os sujeitos a já predisporem de determinada leitura cativa dos fatos, rejeitando o que distingue, compartilhando o que assemelha, sem maiores reflexões acerca do que ali é informado como verdade. Há, portanto, algo de bastante retórico, não meramente pela questão da (im)persuasão possível de ser observada nesse fenômeno, mas, sobretudo, pelo caráter retórico desde a percepção da realidade, pelo movimento cognitivo e argumentativo de seleção do que se divulga e do que se rejeita.

\section{A retórica da pós-verdade}

Segundo Angenot (2008), a argumentação, no fim das contas, é questão de justificação e posicionamento. Com efeito, argumenta-se com vistas a apresentar um ponto de vista, defendê-lo frente ao ponto de vista do outro. A argumentação revela, assim, sempre um processo de identificação entre o sujeito e os valores que fundamentam tal e tal argumentação, as doxas que ancoram toda a empreitada persuasiva. Dito desta forma, conforme nos alerta Meyer (2010), é próprio da identidade (justamente porque é identidade) rejeitar a diferença.

Obviamente, estudar os tipos de argumentação em jogo, no que se convém agora chamar de "a era da pós-verdade", é também um objeto da retórica, porquanto é interesse da tekhné tudo o que remete ao assentimento, seja uma verdade amplamente aceita, seja apenas uma afirmação plausível, possível ou verossímil. Em tempos de pós-verdade, os discursos que circulam pela opinião pública, sobretudo nas redes sociais, contêm todo tipo de proposição, desde as que são possíveis de verificar como verdades, até as que são meras suposições, ou mesmo as que são comprovadamente mentirosas.

Segundo a abordagem retórica de Michel Meyer, o ethos, a dimensão do orador, dos sujeitos produtores de um discurso, é responsável por ser o ponto final dos questionamentos, ou seja, cabe ao ethos a função de se colocar na 
condição de dirimir as distâncias interpostas entre os diferentes indivíduos pelo discurso. No discurso da pós-verdade, contudo, o ethos é a própria instituição das distâncias. Não há interesse dos sujeitos em estabelecer aproximações com o que é divergente. Há, pelo contrário, o movimento do ethos em aumentar a distância com o diferente, porque quanto mais se distancia de outras identidades, menos se correria o risco de absorvê-las.

O pathos, por sua vez, é a dimensão do auditório, a saber, os interlocutores/receptores do discurso e suas emoções acerca de uma questão. Para o filósofo, o discurso, entendido como logos, é sempre resultado do ethos menos o pathos, pela fórmula que denomina de lei da distância (MEYER, 2010). Por assim dizer, é sempre em função de resolver os questionamentos do auditório, administrando suas emoções e tudo o que o afeta, que o orador organiza sua argumentação. Contudo, nos discursos da pós-verdade, sobretudo nos que circulam em redes sociais, o que se percebe é um pathos inflado e um ethos que não dirime as distâncias, não apenas porque não dispõe de condições para tal, mas porque não lhe interessa negociá-las. Isso porque, consoante Meyer (2010, p. 194), a "paixão é o valor reduzido a uma simples reação subjetiva. $E$, inversamente, o valor é a paixão menos a resposta subjetiva e emocional". Nesse sentido, pode-se afirmar que a paixão é a própria incarnação dos valores no sujeito e, para o filósofo, os valores, como absolutos, raramente são negociáveis.

No domínio do logos, pode-se perceber que o discurso de pós-verdade possui algumas características em comuns. Conforme analisa Dunker (2017, p. 29), há três traços que marcam discursivamente a pós-verdade. O primeiro deles é o da aceleração, entendida como um "fenômeno da cultura da performance generalizada, derivada do universo da produção e da soberania do resultado". Em outras palavras, refere-se ao número exacerbado de informações e instrumentos que acabam por dificultar a apreensão cautelosa dos fatos. O segundo traço é a retórica icônica desses discursos, isto é, a quantidade exacerbada de informação que costuma vir em blocos, exigindo uma leitura como um "todo de uma vez", o que ocasiona, com a mesma velocidade, picos de informação e o seu total esquecimento. Um terceiro e último traço discursivo é que a pós-verdade "está muito ligada a certos esquemas de ação e protocolos de funcionamento" (p. 30). De fato, como aqui já exposto, a pós-verdade evidencia o caráter cognitivo das convicções, porquanto revela a pré-programação de determinados estados de pensamento e seus consequentes esquemas de ação. Em outras palavras, 


\section{$\mathrm{El} \square \mathrm{dA}$}

quer-se dizer aqui que os discursos de pós-verdade estruturam-se, cognitivamente, por meio de certos esquemas de pensamento que orientam, de maneira mais ou menos semelhante para todos os "crentes", o modo padrão de funcionamento dos discursos (e, consequentemente, das ações). Há, destarte, uma relação de validade para cada discurso de pós-verdade que não obedece ao critério de factualidade ou de veracidade epistêmica, mas sim a critérios de outros tipos de racionalidade, próprios do regime das convicções, os quais serão brevemente considerados na seção seguinte.

\section{A racionalidade e a convicção: entre valores e paixões}

Conforme apresentado, há, assim, lugar para afirmar que a grande questão da pós-verdade é a superação da "verdade dos fatos" pelo estabelecimento da convicção como critério de validade para um argumento. Vale dizer, ademais, que tendo a convicção como critério de validação, assume-se, automaticamente, os próprios valores a ela subjacentes como fundamento dos posicionamentos e opiniões. Uma vez que os valores são princípios estruturantes do próprio ser enquanto ser-no-mundo, não há como passar desapercebido o fato de que se trata, no fim das contas, não de um desejo de descoberta de uma suposta verdade última, estanque ou definitiva, mas sim de um desejo de manutenção das identidades e das verdades que the são convenientes para tanto. Há aí uma questão ética subjacente. Weber (1998, p. 114, grifo nosso) afirma que "o partidário da ética da convicção só se sentirá 'responsável' pela necessidade de velar em favor da chama da doutrina pura, a fim de que ela não se extinga". Segue adicionando: "seus atos [...] visam apenas àquele fim: estimular perpetuamente a chama da própria convicção". Há que se entender que ambos os conceitos estão ligados, conforme aponta Boudon (2017), à noção de racionalidade do próprio Weber. Nas palavras de Boudon, a noção de ética "remete a uma teoria da racionalidade, já que repercute a distinção entre racionalidade axiológica e racionalidade instrumental" (BOUDON, 2017, p. 51), conforme se verá adiante.

Com efeito, o caráter íntimo de uma convicção está justamente atrelado à relação de identificação entre o sujeito, os seus valores e paixões com os argumentos que se mostrem familiares para si em termos de posicionamento. Desse modo, a relação que se tem é sempre uma relação erística e combativa, na medida em que haverá sempre, por parte do sujeito, um movimento "natural” de manutenção da "chama de sua convicção" e, logo, de resistência 
ao ponto de vista do outro, porquanto é uma resistência aos valores desse outro que, frequentemente, são antagônicos aos seus. Perelman e OlbrechtsTyteca (2005) afirmam que todo ato é ato de uma pessoa, ou seja, é manifestação de um sujeito, com seus valores encarnados. Nesse sentido, todo conflito entre pessoas, odioso, intolerante e tendencioso ao diálogo de surdos é, antes, um conflito de valores. Nascimento (2018), inspirado na teoria do filósofo Max Scheler, afirma que todo amor ao outro é, na verdade, amor aos valores desse outro, assim como todo ódio é igualmente ódio a seus valores, ou ainda, ódio aos valores amados pelo outro. Segundo ele:

[...] quando se ama determinado valor, dele se aproxima, o sujeito abre-se para possível persuasão se há uma congratulação com aquele valor; quando se odeia, não há abertura para a persuasão nem para a compreensão [... ] (NASCIMENTO, 2018, p. 202).

Meyer (2010, p. 189-190) afirma que os valores são como "crenças sempre relativas, que se opõem entre si, assim como os grupos que as reivindicam" " $\mathrm{e}$ que não se trata "mais [de] questão de validade nem de adesão, mas de combate, valores contra valores, cuja vitória é a legitimação última" (p. 190). Uma vez que se entendem os distintos valores como crenças em combate, a persuasão pela racionalidade de um argumento e pela verdade irrenunciável de um discurso - ao menos em termos de discurso político, lugar de pathos inflado e onde a identificação entre o sujeito e seus valores mostra-se ainda mais exacerbada - dá lugar à convicção, à força inabalável das crenças que formam opiniões sólidas acerca de um objeto, evento ou fenômeno. A esse problema, Meyer (2010) chama de ilusão retórica, que consiste em:

[...] crer que os argumentos de cada um contam, enquanto que o objeto da reunião e do diálogo é sobretudo o reconhecimento mútuo do papel de cada um, inflado por este jogo simples, em que se negocia sua imagem (a distância), e não uma resposta, que acaba por ser esquecida e que era, na verdade, secundária ou já decidida de antemão (MEYER, 2010, p. 191).

Destarte, a ilusão retórica apontaria para uma proeminência da validade axiológica em detrimento da validade epistêmica de determinada "verdade". Boudon (2017) afirma, com efeito, que as crenças e as convicções podem ser explicadas através de diversas óticas e compreensões, as quais foram desenvolvidas em diferentes teorias e escolas sociológicas ao longo da história do pensamento social. A primeira dessas compreensões é a

\footnotetext{
${ }^{9}$ No original: “[...] croyances toujours relatives, qui s'opposent entre elles, comme les groupes qui s'en réclament", no original.
} 
concepção dualista, a qual divide as crenças (e consequentemente as convicções) em dois grupos (as bem-fundamentadas e as mal fundamentadas; as boas e as más; as racionais e as irracionais etc.). Nesse sentido, caminha Aron (2016), inclusive, lançando mão da metáfora do ópio para se referir à ideologia como a droga que entorpecia os intelectuais de sua época. Não diferentemente, pode-se conceber, de maneira igualmente dualista, a concepção marxista (que se mostrará também utilitarista) das convicções, estabelecendo sempre a convicção contrária àquela proveniente das classes operárias como sendo irracional, tal como se pode perceber na concepção de habitus de Pierre Bourdieu, na qual é sempre o habitus da classe burguesa e das elites a razão de todo mal, injustiça e desigualdades.

A racionalidade instrumental, por sua vez, possui entre suas variantes duas grandes teorias ou movimentos de racionalidade: a teoria utilitarista, que procura "reduzir o verdadeiro, o bom, o legítimo e os outros valores a um valor último, a utilidade, seja a utilidade para este ou aquele grupo ou a utilidade para um indivíduo" (BOUDON, 2017, p. 30, grifo nosso), e, de maneira análoga, o movimento pragmatista, o qual "partilha com o utilitarismo a intuição fundamental de que os valores e as convicções têm uma função de adaptação, mesmo se aqueles que aderem a eles não sentem isso" (BOUDON, 2017, p. 31). Ainda segundo o sociólogo francês, o que diferenciaria o utilitarismo do pragmatismo é que este último "ressalta as consequências das emoções na explicação da ação, das crenças e dos comportamentos" (Ibidem, p. 31). Há, no entanto, mais aproximações do que distanciamentos entre os movimentos, uma vez que se pode compreender o fundamento da ação tanto pelas emoções subjacentes como pelas ideologias e "boas razões" que projetem uma "utilidade" para os sujeitos. Em miúdos: a racionalidade pragmática diria respeito aos efeitos patêmicos de determinada ação, o que, por si só, seria já a causa de sua tomada, enquanto a racionalidade utilitarista concerne, sobretudo, à utilidade, em termos racionais, de uma determinada ação. No entanto, ambas dizem respeito a uma instrumentalização da racionalidade para fins de dominação e não necessariamente para fins heurísticos de compreensão das verdades no mundo. Essa seria, por exemplo, a explicação da lógica marxista que sustenta a veracidade de uma ideia a partir de uma instrumentalização, ou seja, "a partir de sua utilidade em favor desta ou daquela causa política" (BOUDON, 2017, p. 33).

Com efeito, a racionalidade utilitarista e a racionalidade pragmatista parecem se encontrar com frequência como causa conjunta de diversos 
$\mathrm{EI} \square \mathrm{dA}$

Revista Eletrônica de Estudos Integrados em Discurso e Argumentação, Ilhéus, n. 18, abr.2019.

fenômenos sociais, notadamente, o referido caso dos discursos de pósverdade e das fake news que circulam pelas redes sociais em tempos contemporâneos, na medida em que ambas pressupõem a existência de uma racionalidade axiológica. Esse tipo de racionalidade se explicaria, fundamentalmente, pelo ato de conceber a causa das ações a partir dos valores em questão. E, nesse ponto, não se pode dissociar os valores das paixões (pragmatismo), tampouco das opiniões acerca do que se pareça mais útil e conveniente a determinada forma de ver o mundo (utilitarismo).

Nesse sentido, valores e paixões estão sempre em jogo quando se busca explicar a razão das ações sociais na era da pós-verdade, ao menos em boa parte dos casos. Na medida em que o sujeito ama os seus próprios valores e, consequentemente, odeia os valores contrários, estabelece-se a tendência de acreditar, sem maiores sacrifícios e esforços intelectuais e reflexivos, em todo discurso no qual se vislumbrem os mesmos valores subjacentes. De maneira inversa, há, imediatamente, a tendência ao movimento da repulsa ou rejeição ao discurso ideologicamente contrário, justamente por não haver aí compartilhamento de valores. Há, assim, conforme assinala Dunker (2017, p. 38), um movimento a "confirmar conclusões tendenciosas" no discurso da pós-verdade.

Como acima já dito, os sujeitos parecem interagir, na era da pós-verdade, pelo critério da familiaridade. Apenas o que é familiar, leia-se, o que possui identidade aos meus valores e, consequentemente, o que incita paixões comuns entre os iguais, será passível de ser acreditado. Estabelece-se, aqui, o próprio pressuposto da distinção de códigos retóricos que impossibilitariam o diálogo e a persuasão (ANGENOT, 2008). Safatle (2017), no mesmo sentido, afirma que tal código, tal "língua em comum” não é a língua em si, mas o:

[...] conjunto de valores, a gramática que organiza a minha sintaxe, a compreensão do que é um enunciado válido ou não. Para dialogar é necessário pressupor uma gramática comum. Mais do que isso. É necessário pressupor que todos os conflitos e todas as posições conflitantes farão sempre referência à mesma gramática comum (SAFATLE, 2017, p. 128)

Ademais, o ato de compartilhamento de uma informação pelas redes sociais, sejam elas notícias factuais ou fake, obedece, assim, a um desejo próprio das convicções, que é o de, apesar de sólida em si mesma, querer sempre se valer em detrimento de outras, na busca incessante pelo estabelecimento de uma única verdade ou, ao menos, uma verdade superior. 


\section{$\mathrm{El} \square \mathrm{dA}$}

\section{Considerações finais}

Pode-se dizer, enfim, que a noção de pós-verdade, apesar de frequentemente aproximada à de mentira, apresenta maior complexidade, na medida em que se refere, antes de tudo, à indisponibilidade dos sujeitos à persuasão devido ao caráter sólido de suas próprias crenças e convicções. Renunciar a uma verdade é, destarte, renunciar a si mesmo, à sua identidade, às suas formas de vida e existência no mundo. Nesse sentido, há no sujeito o desejo por determinada verdade, não pela verificação da relação de factualidade de uma determinada informação ou fato, mas antes por dizer respeito às mesmas crenças e, portanto, comungar dos mesmos valores, o que deflagraria uma racionalidade axiológica como princípio da formação das opiniões políticas em detrimento de quaisquer outras razões.

O grande desafio teórico para a existência da pós-verdade é o fato de que, na grande parte dos casos, uma verdade tende a prevalecer. De fato, há muitas verdades em disputa que não são versões possíveis do mesmo fenômeno, mas sim uma verdade entre variadas interpretações equivocadas (o que faz parte do jogo político) e, nesses casos, não há como resistir à força do apodítico. Todavia, não se pode negar que há, decerto, muito pouco de apodítico nos fatos sociais, e, nessas situações, prevalece a batalha entre os impérios retóricos, batalha esta de que apenas a história poderá narrar os vencedores. Num império carnavalesco de verdades de fantasia, parece mesmo louco o rei que, por engano, mostrou-se nu.

\section{Referências}

ANGENOT, Marc. Dialogues de sourds: traité de rhétorique antilogique. Paris: Mille et une nuits/Fayard, 2008.

ARENDT, Hannah. 0 que é política? Editoria de Ursula Ludz. Tradução: Reinaldo Guarany. 8. ed. Rio de Janeiro: Bertrand Brasil, 2009.

ARON, Raymond. O ópio dos intelectuais. São Paulo: Três Estrelas, 2016.

BOUDON, Raymond. Crer e saber: pensar o político, o moral e o religioso. Tradução: Fernando Santos. São Paulo: Ed.Unesp, 2017.

BARTHES, Roland. Efeito de real. In: Vários autores. Literatura e semiologia. Petrópolis: Vozes, 1971. 
BRAGA, Renê Morais da Costa. A indústria das fake news e o discurso de ódio. In: PEREIRA, Rodolfo Viana (Org.). Direitos políticos, liberdade de expressão e discurso de ódio. Volume I. Belo Horizonte: IDDE, 2018. p. 203-220.

BRONNER, Gérald. La démocratie des crédules. Paris: PUF, 2013.

CHARAUDEAU, Patrick. La conquête du pouvoir: Opinions, persuasion, valeurs. Les discours d'une nouvelle donne politique. Paris: L'harmattan, 2013.

DUNKER, Christian. Subjetividade em tempos de pós-verdade. In: DUNKER, Christian et al. Ética e pós-verdade. Porto Alegre/São Paulo: Dublinense, 2017.

EMEDIATO, Wander. Dimensões e face da mentira no discurso político. In: EMEDIATO, Wander (Org.). Análises do Discurso Político. Belo Horizonte: NAD/FALE, 2016.

FOUCAULT, Michel. Microfísica do poder. Rio de Janeiro: Graal, 1979.

KEYES, Ralph. The post-truth era: dishonesty and deception in contemporary life. New York: St. Martin's Press, 2004.

MAQUIAVEL, Nicolau. O príncipe. Tradução: Maurício Santana Dias. São Paulo: Penguin Classics Companhia das Letras, 2010.

MEYER, Michel. Principia Rhetorica: une théorie générale de l'argumentation. Paris: PUF, 2010.

POST-TRUTH. Oxford Dictionary. 2016. Disponível em: https://en.oxforddictionaries.com/definition/post-truth. Acesso em: 01 ago. 2018.

PERELMAN, Chaim; OLBRECHTS-TYTECA, Lucie. Tratado da argumentação: a nova retórica. Tradução: Maria Ermantina Galvão. 2. ed. São Paulo: Martins Fontes, 2005.

SAFATLE, Vladimir. É racional parar de argumentar. In: DUNKER, Christian et al. Ética e pós-verdade. Porto Alegre/São Paulo: Dublinense, 2017.

SILVA, Lucas Nascimento da. Análise dialógica da argumentação: a polêmica entre afetivossexuais reformistas e cristãos tradicionalistas no espaço político, 2018. Tese (Doutorado em Letras), Universidade Federal da Bahia, 2018.

WEBER, Max. Ciência e política: duas vocações. Tradução: Leonicas Hegenberg e Octany Silveira da Mota. 4. ed. São Paulo: Cultrix, 1998.

\section{Forma de citação sugerida}

SEIXAS, Rodrigo. A retórica da pós-verdade: o problema das convicções. EID\&A Revista Eletrônica de Estudos Integrados em Discurso e Argumentação, Ilhéus, n. 18, p. 122-138, abr.2019. DOI dx.doi.org/10.17648/eidea-18-2197. 